Kennedy A. Nejar'

Isabela M Benseñor'

Paulo A. Lotufo"

\section{Sunshine and suicide at the tropic of Capricorn, São Paulo, Brazil, 1996-2004}

\section{Luz solar e suicídio no trópico de Capricórnio, São Paulo, Brasil, 1996- 2004}

\begin{abstract}
Several studies have confirmed seasonal variation in suicide rates according to hours of sunshine. The suicide pattern was assessed in São Paulo, southeastern Brazil, at the tropic of Capricorn from 1996 to 2004. Poisson regression was employed to estimate parameters of seasonality, as well as to verify associations for each day between daylight duration and suicide. During the nine-year study period, there were 3,984 suicides $(76.9 \%$ in men; median age $=38.7$ years old). Seasonal averages of suicides were similar, as were monthly averages. Poisson regression did not reveal any association between suicide rates and hours of sunshine $(\mathrm{p}=0.45)$ for both sexes. In conclusion, no seasonal pattern was observed for suicides.
\end{abstract}

KEY WORDS: Suicide. Sunlight. Temporal distribution. Poisson distribution. Brazil.

RESUMO

Estudos epidemiológicos têm confirmado que as taxas de suicídio apresentam variação sazonal relacionada às horas de insolação. $\mathrm{O}$ padrão de suicídios foi analisado na cidade de São Paulo, Brasil, no trópico de Capricórnio, de 1996 a 2004. A regressão de Poisson foi utilizada para estimar padrões de sazonalidade, bem como verificar a associação dia-a-dia entre duração da insolação e suicídio. Durante os nove anos houve 3.984 suicídios (76,9\% homens; mediana de idade $=38,7$ anos). As médias de suicídio por estação do ano e por mês de suicídio foram similares. Segundo a regressão de Poisson, não houve associação entre insolação e suicídio $(\mathrm{p}=0,45)$ para ambos os sexos. Conclui-se que não houve padrão sazonal de suicídios na cidade de São Paulo.

DESCRITORES: Suicídio. Luz solar. Distribuição temporal. Distribuição de Poisson. Brasil. 


\section{INTRODUCTION}

In his masterpiece, "Suicide," Emile Durkheim noted that "when the days grow longer quickly, suicides increase greatly," i.e., suicide has a peak in the spring or summer and a trough in winter, which has been confirmed in studies conducted in the Northern Hemisphere. ${ }^{4,5}$ Although few studies have addressed this issue in the Southern Hemisphere, their findings were similar. ${ }^{2}$ They have shown that higher suicides rates occur during months with more daily sunlight hours. In contrast, in Singapore (at the Equator line), a country with little daily sunlight variation throughout the year, there are no seasonal fluctuations of suicide rates. ${ }^{3}$ These studies suggest that sunshine-regulated hormones, such as melatonin, may have a role in triggering suicide. If true, one would expect to see greater seasonal variation in suicide risk with increasing distance from the Equator.

To test this hypothesis, suicide pattern in a city located at the tropic of Capricorn was investigated.

\section{METHODS}

An ecological study was carried out correlating daily data from suicide and solar irradiance and temperature, in the city of São Paulo, Southeastern Brazil, from 1996 to 2004. The city is crossed by the tropic of Capricorn (2332'51" latitude, $46^{\circ} 38^{\prime} 10^{\prime \prime}$ 'longitude) and situated at an altitude of $760 \mathrm{~m}$, with an area of $1,525 \mathrm{~km}^{2}$ and a resident population of 10,434,252 inhabitants, according to the 2000 Brazilian Census. Seasons of the year were defined as summer (December-January-February), fall (March-April-May), winter (June-July-August) and Spring (September-October-November)

Data were collected from death certificates classified as suicide $\left(10^{\text {th }}\right.$ International Classification of Diseases: codes X60-X84) in the city of São Paulo in daily series from 1996 to 2004 obtained from Programa de Aprimoramento de Informação de Mortalidade (PROAIM), the official health statistics of the municipality. All presumed cases of deaths attributed to suicide are required to be autopsied in the medical forensic department by two coroners.

There are two meteorological stations located in the northern and southern area of the city. No differences were found for sunshine and temperature measurements between the two stations. In the northern one, data were collected on bright sunlight hours, defined as the period of time during which sunlight intensity was sufficient to burn a trace on a standard chart when focused with a glass sphere (Campbell-Stokes recorder). In the southern station, data were collected using a pyranometer (Eppley Lab Inc., model PBW) to determine the global solar irradiation (in megajoule $/ \mathrm{m}^{2}$ ).
First, temporal changes of suicide during the study period were tested to avoid that increased or decreased suicide rates could affect seasonal distribution of deaths and, most importantly, the association with sunshine and temperature. Then, the analysis of the series was carried out to detect trends. Since temporal analyses showed significant decrease of suicide rates $(p=0.0002)$, data had to be adjusted using a statistical approach as means of the transformed series to analyze seasonality by months and seasons. Poisson regression variant of the circular normal distribution was applied to estimate parameters of seasonality, as well as to verify associations for each day among meteorological factors and suicide. The statistical package Stata v.7 was used in the analysis.

\section{RESULTS}

During the nine-year study period, there were 3,984 suicides, of which $76.9 \%$ in men. Median age was 38.7 years old. Seasonal suicide averages had similar distribution according to seasons (fall $=107$; winter $=110$; spring $=110$; summer $=112$ ) as were monthly averages (the highest suicide average occurred in August and November and the lowest in September and April). The Figure displays the mean number of suicides as a function of mean direct solar irradiance by month. Poisson regression showed no association between number of suicides by day and direct solar irradiance $(\mathrm{p}=0.45)$. The same results were obtained when hours of daylight were considered. In addition, the results were also not significant for average temperature $(\mathrm{p}=0.34)$. Data analyses according to gender and age group did not show any differences on the seasonal distribution of suicides and the association between sunshine and suicide.

\section{DISCUSSION}

Data studied from the largest city in the Southern Hemisphere showed no seasonal fluctuation of suicide rates. There was also no association between the number of suicides assessed on a daily basis with sunshine and average temperature measurements. The analyses of suicide behavior were consistent when, instead of day, months and seasons were considered as the unit of observation.

The influence of sunshine on suicide risk was proved to be significant in countries with wider fluctuations of solar irradiation throughout the year as in European Nordic countries. ${ }^{4,5} \mathrm{~A}$ less pronounced association was found in temperate zones, ${ }^{2}$ and no association was seen in Singapore, located at the Equator line. ${ }^{3}$ The present study data support the findings of Chew \& McCleary, ${ }^{2}$ who compared suicidal behavior among 28 countries and concluded that seasonal variation in suicide is high in temperate zones (between $30^{\circ}$ and $60^{\circ}$ north and south of the Equator) and low in the tropics. To the 


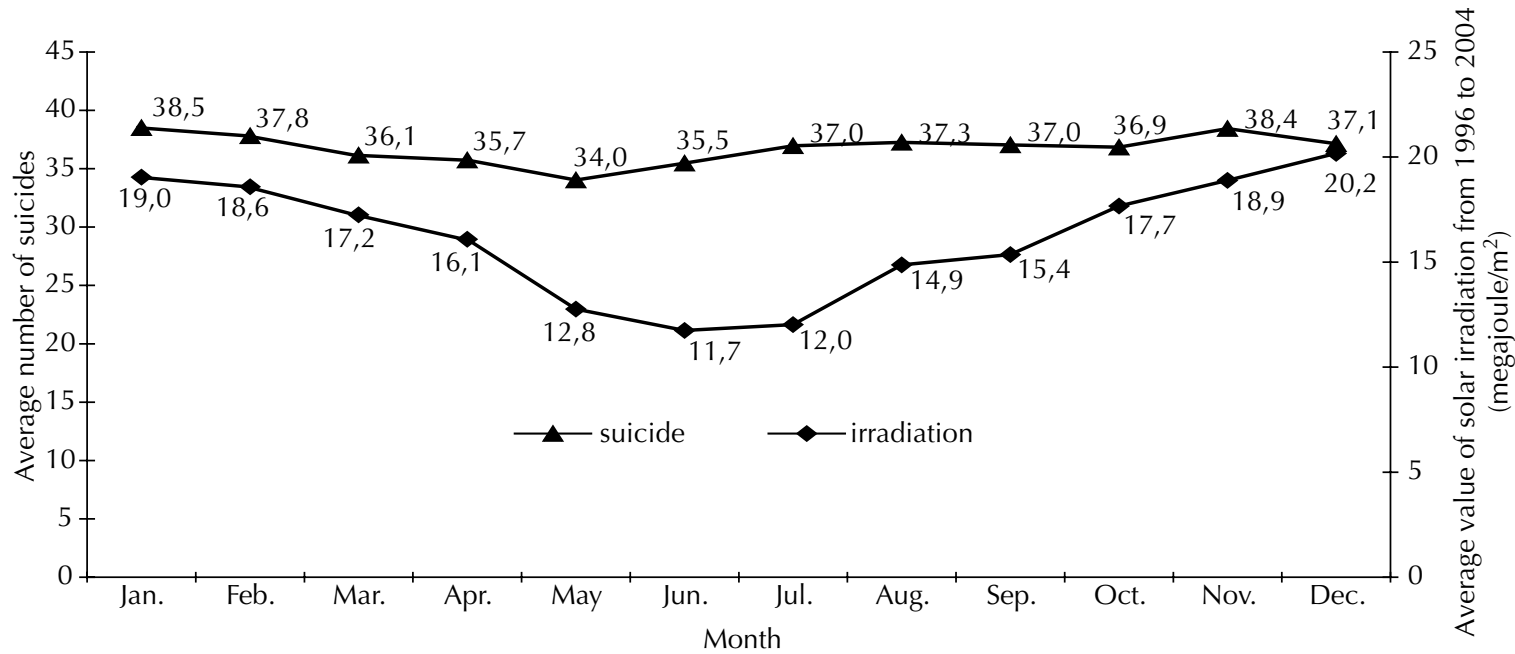

Note: Monthly values include consecutive 3-month periods. For example, values for February were derived from mean values in January, February, and March. The values of March were derived from mean values in February, March, and April.

Figure. Association between suicide rates and solar irradiation. São Paulo, Southeastern Brazil, 1996-2004.

authors' knowledge, there is no data about seasonal changes of suicide in Hawaii, a place located at the same latitude as São Paulo but in the Northern Hemisphere at the tropic of Cancer.

There is a hypothetical role of melatonin metabolism explaining how sunshine or correlated factors are related to suicide. One putative factor emphasized by various authors, including Petridou et $\mathrm{al}^{5}$ would be related to one of several mood regulators, the melatonin variation according to season and differences of solar irradiation. Melatonin secretion has been shown to be abnormal in some severely depressed patients but the majority of these studies were conducted in the Northern Hemisphere. Recently, in São Paulo, a comparison of drug-free depressive patients with healthy volunteers matched for age and gender did not reveal any difference in major urinary metabolite of melatonin, and further matching for body mass index and season did not change these results. ${ }^{1}$

\section{REFERENCES}

1. Carvalho LA, Gorenstein C, Moreno RA, Markus RP. Melatonin levels in drug-free patients with major depression from the southern hemisphere. Psychoneuroendocrinology. 2006;31(6):761-8.

2. Chew KS, McCleary R. The spring peak in suicide: the cross-national analysis. Soc Sci Med. 1995;40(2):22330.

3. Parker G, Gao F, Machin D. Seasonality of suicide
The present study revealed (data not shown) that age-adjusted suicide rates are declining for both sexes. Although, they were adjusted using means of the transformed series to analyze seasonality according to months and seasons it is possible that this decline could affect the seasonality of suicide.

The strengths of the present study included the quality of solar irradiation measurements in the two stations using different methods, and the good quality ascertainment of death in São Paulo by autopsy and further epidemiological surveillance. The study's limitation was the lack of statistical power to identify differences according to gender and/or age groups.

In conclusion, in a large urban area at the tropic of Capricorn, no seasonal fluctuations of suicide rates as well as no association between solar irradiance and suicide rates were seen.

in Singapore: data from the Equator. Psychol Med. 2001;31(3):549-53.

4. Partonen T, Haukka J, Nevanlinna H, Lönnqvist J. Analysis of the seasonal pattern in suicide. J Affect Disord. 2004;81(2):133-9.

5. Petridou E, Papadopoulos FC, Frangakis CE, Skalkidou A, Trichopoulos D. A role of sunshine in the triggering of suicide. Epidemiology 2002;13(1):106-9. 